\title{
18
}

\section{Research Ethics Review}

\author{
Edward Dove
}

\subsection{INTRODUCTION}

Across most jurisdictions today, researchers who propose to involve humans, their tissue and/or their data in a health research project must first submit an application form, which includes the research protocol and attendant documents (e.g. information sheets and consent forms), to one or several committees of experts and lay persons, who then assess the ethics of the proposed research. In some jurisdictions, this review, known as research ethics review, is mandated by law. In these cases, the law may be general ${ }^{1}$ or it may apply to specific kinds of health research, such as clinical trials of an investigational medicinal product ${ }^{2}$ or health research involving adults lacking capacity. ${ }^{3}$ In other jurisdictions, and depending on the type of research project, research ethics review may be required or expected by 'softer' forms of regulation, such as guidelines, policy or custom, with the processes for the review consequently less standardised - and more flexible - than in a rules-based regime.

The principal aim of these research ethics committees (RECs), also known as institutional review boards (IRBs) and research ethics boards (REBs), ${ }^{4}$ is to protect the welfare and interests of prospective (and current) participants and to minimise risk of harm to them. Another aim is to promote ethical and socially valuable research. This phenomenon of evaluating the ethics of proposed health research and determining whether the research may proceed - and on what grounds - has been in existence largely since the $1960 .^{5}$ Originally designed for review of clinical research involving healthy human volunteers, research ethics review has since expanded to cover all fields of health research, including social science-driven health research such as qualitative studies investigating patient experiences with a disease or treatments that they receive. Given their central role in determining the bounds of ethical research, it is unsurprising to learn that RECs have been subject to sustained scrutiny; in many quarters, this has resulted in criticism within the health research and academic community that, among other things, the process of research ethics review is not fit for purpose. The cumulative charge is that research

${ }^{1}$ See e.g. CC 810.30 Federal Act of 30 September 2011 on Research involving Human Beings (Switzerland).

2 See e.g. The Medicines for Human Use (Clinical Trials) Regulations 2004 No. 1031 (UK); Food and Drug Regulations (CRC, c 870), C.05 (Division 5 - Drugs for Clinical Trials Involving Human Subjects) (Canada).

3 See e.g. Mental Capacity Act 2005 (England and Wales) and Adults with Incapacity (Scotland) Act 2000.

4 Henceforth in this chapter I will use the terminology 'REC' as shorthand.

5 L. Stark, Behind Closed Doors: IRBs and the Making of Ethical Research (University of Chicago Press, 2012); A. Hedgecoe, Trust in the System: Research Ethics Committees and the Regulation of Biomedical Research (Manchester University Press, 2020). 
ethics review by committees promotes a wicked combination of inexpert review, inconsistent opinions, duplicative work, mission creep and heavy-handed regulation of health research.

This chapter places this charge at the focal point. In what follows, I chart the process of research ethics review with a view towards arguing that RECs have become regulatory entities in their own right and very much are a form of social control of science. As I detail, while RECs are far from perfect in terms of regulatory design and performance, they do perform, at least in principle, a valuable role in helping to steward research projects towards an ethical endpoint. In what follows, I analyse the nature and aims of research ethics review and the body of academic research regarding research ethics review. In so doing, this chapter also offers a critique of existing work and suggests some future directions for both the regulatory design of research ethics review and also researching the field itself.

\subsection{RESEARCH ETHICS REVIEW AS A REGULATORY PROCESS}

Many scholars have long viewed the notion of evaluation of the ethics issues of a proposed research project by a committee of people qualified in some way to assess the project's ethics as necessary, but not necessarily sufficient, for the successful functioning of, and securing of public trust in, health research. RECs, it is said, reflect a pragmatic system of 'social control' by researchers' academic and community peers. As William May opined in 1975: 'The primary guarantee of protection of subjects against needless risk and abuse is in the review before the work is undertaken. [...] [I]t is the only stage at which the subject can be protected against needless risk of injury, discomfort, or inconvenience'. ${ }^{6}$ John Robertson similarly concluded in 1979: "The [REC] is an important structural innovation in the social control of science, and similar forms are likely to be developed for other such controversial areas'. 7 By influencing research in an event-licensing capacity - that is, by offering opinion on and approval (or rejection) of a research project before it commences - RECs are seen to mitigate risks to researchers, participants and society. To this extent, research ethics review can be cast as a regulatory process.

As RECs have become more entrenched in the regulatory apparatus of health research over the past half-century, they have come to hold tremendous power over how research is shaped and thus, influence over what knowledge is produced - as well as how the relationship between a researcher and a research participant is circumscribed. As Laura Stark observes, ethics committees 'are empowered to turn a hypothetical situation (this project may be acceptable) into shared reality (this project is acceptable). [...] [T] hey change what is knowable'.

But it remains unclear what exactly constitutes research ethics review. Indeed, we might ask whether RECs engage in ethics deliberation at all - and, just as critically, whether this matters to fulfilling their putative regulatory role of assessing the relevant ethics issues in a project. Perhaps the challenge lies with the term 'research ethics review'. This suggests less of a focus on formulaic, bureaucratic - arguably synonymous with 'regulatory' - answers to questions (e.g. 'Is there informed consent?'; 'Have they used our consent form template?') and more of a focus on seeking deeper, more philosophically engaged answers to penetrating questions, such as: 'Do we really need informed consent here?'; 'What sort of alternative and preferable safeguards

\footnotetext{
${ }^{6}$ W. May, 'The Composition and Function of Ethical Committees', (1975) Journal of Medical Ethics, 1(1), $23-29,24$.

7 J. Robertson, 'Ten Ways to Improve IRBs', (1979) Hastings Center Report, 9(1), 29-33, 29.

8 Stark, Behind Closed Doors, p. 5.
} 
might there be and why?'; 'Is this research in the public interest?'; or 'What public good might come from this research and is the financial and social cost commensurate?'.

What is reasonably clear is that a REC provides a favourable opinion only if it is assured that the ethics issues in the proposed research are appropriately addressed by the researcher - and sponsor - before the project proceeds. As the issues will vary depending on the research in question, REC members receive training and guidance about the issues they should consider, both in general and in particular cases. For example, according to the Governance Arrangements for Research Ethics Committees (GAfREC), which is a formal governance document for National Health Service (NHS) RECs in the UK: "The training and guidance reflect recognised standards for ethical research, such as the Declaration of Helsinki, and take account of applicable legal requirements'. ${ }^{9}$ If REC members learn about what research ethics is supposed to entail according to 'recognised standards' and take account of 'applicable legal requirements', we might reasonably ask whether the REC meetings themselves reflect a kind of instantiated deliberative decision-making ethics - that is, ethics as input, process, and outcome where members individually and collectively evaluate and come to decide on the ethical acceptability of research proposals by invoking and deliberating on standards and requirements more than (ethical) norms or principles. If this is so, the REC, as a form of a decision-making body, need not necessarily 'do ethics' at all.

Some evidence of this comes when we shift our gaze from theory to practice. As Mary DixonWoods and colleagues have found in their empirical investigation of REC opinion letters to researchers:

Though clearly RECs are making firm recommendations to researchers in these [previously discussed] examples of both inconsistent and consistent advice, the source of ethical authority for the REC in coming to their conclusions is rarely explicit in the letters. GAfREC - which provides the framework within which RECs are expected to work - is not referred to in any of the letters in our sample. Specific ethical principles or even guidelines are rarely invoked explicitly, and when they are, it is to authenticate or legitimise the decisions of the committee $[\ldots] .^{10}$

If the REC opinion letter is a reasonably accurate reflection of the contents of a REC meeting's discussion, then there is some doubt as to whether ethical rules, norms or principles are openly discussed. Other empirical research has affirmed this doubt. ${ }^{11}$

Yet, the names bestowed upon these bodies by many jurisdictions ('ethics committees' or 'ethics boards'), and the related expectation that they should engage in research ethics review and related criticism that they do not do enough of this - may, in fact, be somewhat misplaced. I have suggested through my own empirical research that as RECs become institutionalised and professionalised, acting as multi-faceted and multidisciplinary micro-regulators of health research, and as further national and international regulations come into force that impact health research, RECs might be expected to act more as risk-assessing 'health research regulatory committees' writ large. ${ }^{12}$ Somewhat similarly, based on her own recent empirical research, Sarah Babb makes the case that IRBs in the USA have transformed from academic committees to

9 Health Research Authority, 'Governance Arrangements for Research Ethics Committees', (2020), para 5.3.1.

${ }^{10}$ M. Dixon-Woods et al., 'Written Work: The Social Functions of Research Ethics Committee Letters', (2007) Social Science \& Medicine, 65(4), 792-802, 796.

${ }^{11}$ M. Fitzgerald et al., 'The Research Ethics Review Process and Ethics Review Narratives', (2006) Ethics \& Behavior, 16(4), 377-395.

${ }^{12}$ E. Dove, Regulatory Stewardship of Health Research: Navigating Participant Protection and Research Promotion (Cheltenham: Edward Elgar, 2020). 
'compliance bureaucracies', where specialised administrative staff members define and apply federal regulations. ${ }^{13}$ Even if RECs do not engage in something approaching truly substantive ethics deliberation, and this is (partly) accepted as an outcome of practical constraints (e.g. limited resources and pressed time), might they still be able to fulfil their aim of targeting areas of health research that pose moral concern, and might they still be able to mitigate the manifestation of those concerns?

Indeed, I would argue that it is not necessarily problematic to acknowledge that RECs rarely engage in deep ethics deliberation. RECs are a valuable regulator in health research, and so if there are criticisms of them, we should look to those criticisms that speak to their regulatory functions - procedures, performance and so on - more than the absence or presence of ethics deliberation per se. By focusing here, we may come to see that concerns about efficiency, effectiveness, proportionality, reduced burden and so on, must be addressed more directly. Acknowledging this is not to say that RECs cannot spot and deal with thorny ethics issues when or if they arise, but it does allow us to be arguably more accurate and honest to cast them for what they are: regulators with a gatekeeping and promotional role about getting safe and good science done.

Let us, then, look at some of the persistent criticism of the research ethics review process that speak to the regulatory functions of RECs.

\subsection{REC CRITICISMS: POOR DESIGN AND PERFORMANCE AND THE FETISHISATION OF CONSENT}

For as long as they have existed, RECs have been subject to opprobrium from the research community and academic commentators, mainly because they are seen as under-, over- or simply mis-regulated bureaucratic bulwarks against otherwise ethical, minimally risky or nonrisky research. For years, research into RECs has revealed a high level of variation of decisionmaking processes in RECs ${ }^{14}$ and dissatisfaction from various stakeholders. ${ }^{15}$ These criticisms can be grouped into concerns about (a) design and performance and (b) the fetishisation of consent.

\subsubsection{Poor Design and Performance}

Many of the problems scholars have identified with research ethics review have been due both to weak regulation - which contributes to procedural and substantive inconsistency of decisionmaking - and also over-regulation - which contributes to duplicative review and cumbersome and complex thickets of disproportionate regulation for research that presents minimal risk. ${ }^{16}$ In their review of US IRBs, Emanuel and colleagues identified fifteen 'problems' and grouped them into three broad categories: (1) structural problems deriving from the organisation of the

13 S. Babb, Regulating Human Research: IRBs from Peer Review to Compliance Bureaucracy (Palo Alto, CA: Stanford University Press, 2020).

${ }^{14}$ See e.g. B. Barber et al., Research on Human Subjects: Problems of Social Control in Medical Experimentation (New York: Russell Sage Foundation, 1973). See also Dixon-Woods et al., 'Written Work', 796.

15 See e.g. G. Alberti, 'Local Research Ethics Committees: Time to Grab Several Bulls by the Horns', (1995) BMJ, 311(7006), 639-640; K. Jamrozik, 'The Case for a New System for Oversight of Research on Human Subjects', (2000) Journal of Medical Ethics, 26(5), 334-339; C. Warlow, 'Clinical Research Under the Cosh Again', (2004) BMI, $329(7460), 241-242$.

${ }^{16}$ G. Laurie and S. Harmon, "Through the Thicket and Across the Divide: Successfully Navigating the Regulatory Landscape in Life Sciences Research', in E. Cloatre and M. Pickersgill (eds), Knowledge, Technology and Law (London: Routledge, 2014), pp. 121-136. 
system as established by the US federal regulations, (2) procedural problems stemming from the ways in which individual IRBs operate, and (3) performance assessment problems resulting from the absence of systemic assessment of current protections. ${ }^{17}$ Arguably, many of these structural, procedural and performance assessment problems also could be identified in RECs in other jurisdictions.

Indeed, the main design and performance concerns with the research ethics review process commentators have identified over the years include:

- inconsistency in procedures and substantive decisions within and across committees;

- delays or impediments to research due to slow-moving RECs that have no built-in efficiency incentive;

- cumbersome bureaucratisation and standardisation of application forms that are ill-suited to different types of research, that slow and muddy the process of ethics review and that lead to heavy administrative burdens for researchers;

- distortion of research methods imposed by RECs who may not be trained in research methods and are not qualified (or expected) to judge the scientific merit of applications;

- over- or exclusive reliance on prior (ex ante) review that inadequately assures that the actual conduct of research is in accordance with ethical standards;

- imposition of inappropriate consent requirements in certain types of research projects (e.g. surveys, behavioural intervention studies) that can lead to potential selection bias in participation and responses; and

- increased risk of unethical research, in part due to the ever-growing length of information sheets that participants do not bother to read, and also in part due to lengthy application forms that researchers and REC members alike either may not adequately read or quickly complete - in other words, the insidious growth of a 'tick-box mentality'. ${ }^{18}$

The cumulative account of these concerns suggests that better regulation is needed to improve the efficiency and effectiveness of research ethics review by RECs, and this may entail, among other things, streamlining existing regulation, enacting robust standard operating procedures (SOPs), designing templates tailored to the specific type of research project, and embedding in regulation and policy the emerging notion of stewardship. But before I address these ways forward, I now turn to a second persistent criticism of RECs, namely their fetishisation of consent.

\subsubsection{The Fetishisation of Consent}

Another major criticism of RECs centres on their putatively over-bearing emphasis on consent forms and information sheets, and minute wordsmithing of both, that leads to inevitable elongation of the documents and thereby increased risk of non- or miscomprehension by participants, which ironically may lead to other harms not related to the research, such as stigmatisation or disrespect. Since at least the $1960 \mathrm{~s},{ }^{19}$ commentators have argued that consent cannot and should not act as a stand-alone rampart to prevent unethical research. Yet many consider that RECs disproportionately fixate on consent as a locus for determining and setting

${ }^{17}$ E. Emanuel et al., 'Oversight of Human Participants Research: Identifying Problems to Evaluate Reform Proposals', (2004) Annals of Internal Medicine, 141(4), 282-291.

${ }_{18}$ Many of these criticisms are explored in R. Klitzman, The Ethics Police? The Struggle to Make Human Research Safe (Oxford University Press, 2015).

19 H. Beecher, 'Ethics and Clinical Research', (1966) New England Journal of Medicine, 274(24), 1354-1360. 
researchers' ethical behaviour, demonstrating 'the acme of self-defeating ritual compliance'. ${ }^{20}$ Perhaps it is because 'these [consent] documents constitute one of the few aspects of researcher interactions with subjects - a very downstream process - that committees feel they can control. ${ }^{21}$

This bureaucratic addiction to procedure and process, coupled no doubt with an uptick in legal - albeit siloed - regulation of health research, has led to a legalisation in the workings of RECs, which is to say: a fetishisation for more forms, longer forms and ongoing insistence on boiler-plate language tacked on to information sheets and consent forms so that RECs and institutions protect themselves and others from liability. Consent is treated as a panacea for all ethical concerns, ${ }^{22}$ a kind of Pollyanna-ish hope that, 'If only we can inject all possible risks and relevant information into the form, then participants can truly exercise their autonomy'. This is not the 'good kind' of REC legalisation William Curran envisioned in 1969, replete with a common law-like generalisable body of precedents and principles of procedure and substance that allow the process of deliberation to flourish. ${ }^{23}$ Instead, it is the troubling kind: rigid and overly standardised, treating ethics as a tick-box, form-ridden, technocratically structured event. Once again, this militates against ethics committees actually 'doing ethics' in the genuine sense that is understood of that discipline.

Given the groundswell of criticisms over the years, what, then, might be the future directions for research ethics review as a core process in health research regulation, and what might be the future directions for researching research ethics review to assess what is working well and not so well?

\subsection{FUTURE DIRECTIONS FOR RESEARCH ETHICS REVIEW}

While many support the underlying idea of ex ante ethics review by a competent committee as a means to protect and promote the rights, interests and welfare of participants, as this chapter has observed, many also have expressed dissatisfaction with the structure and function of the ethics review system and the individual processes of RECs. Multiple regulatory techniques and instruments have been employed over the years in the hopes of remedying the myriad problems attributed to RECs, foremost the concerns of inefficiency and ineffectiveness.

Scholars have proposed a number of changes to the regulatory design of research ethics review. For the purposes of this chapter, I want to focus on three that have gained attention recently and may be among the most promising: streamlining, standardisation and stewardship.

\subsubsection{Future Directions for Regulatory Design}

A number of jurisdictions are now streamlining the process of research ethics review in at least two ways. First, they have introduced proportionate review systems, whereby a research project that is deemed by assessors to present no (or limited) material ethics issues undergoes a lightertouch review. In the UK, for example, under the Health Research Authority's (HRA)

${ }^{20} \mathrm{~S}$. Burris and J. Welsh, 'Regulatory Paradox in the Protection of Human Research Subjects: A Review of Enforcement Letters Issued by the Office for Human Research Protection', (2007) Northwestern University Law Review, 101(2), $643-685,678$.

${ }^{21}$ Klitzman, The Ethics Police, p. 139.

${ }^{22}$ See e.g. S. Burris and K. Moss, 'US Health Researchers Review Their Ethics Review Boards: A Qualitative Study', (2006) Journal of Empirical Research on Human Research Ethics, 1(2), 39-58.

23 W. Curran, 'Governmental Regulation of the Use of Human Subjects in Medical Research: The Approach of Two Federal Agencies', (1969) Daedalus, 98(2), 542 -594. 
Proportionate Review Service, such projects are reviewed via email correspondence, teleconference or at a face-to-face meeting by a sub-committee - comprising experienced expert and lay members - rather than at a full meeting of a REC. ${ }^{24}$ The final decision is notified to the applicant by email within twenty-one calendar days of receipt of a valid application, which is a faster turnaround time than an application that goes to a full-committee review. Second, a group of efforts are underway internationally to streamline multiple REC review of multi-site research projects, which is seen as duplicative and disproportionate. ${ }^{25}$ Since 2004 , the UK requires only one NHS REC opinion per research project, even if the project involves multiple sites in the country. In the USA, since 2020 , a revised rule in the Federal Policy for the Protection of Human Subjects better known as the 'Common Rule' - generally requires US-based institutions that receive federal funding and are engaged in cooperative research projects (i.e. projects covered by the Common Rule that involve more than one institution in the USA) to use a single IRB for that portion of the research that takes place within the USA if certain requirements are met. ${ }^{26}$ This 'sIRB rule' reflects a growing effort by regulators and policymakers in countries around the world - including Uganda, ${ }^{27}$ Canada $^{28}$ and Australia ${ }^{29}$ - to reduce the procedural inefficiencies, redundancies, delays and research costs that have become synonymous with the absence of research ethics review mechanisms designed for multi-site health research projects. ${ }^{30}$

A number of jurisdictions are also working on standardisation of the processes involved in ethics reviews, with the aim of achieving more consistent outcomes in review and fairness to applicants. The Care Act 2014 in the UK, for example, requires the HRA to co-operate with several other regulatory authorities in the exercise of their respective functions relating to health or social care research, "with a view to co-ordinating and standardising practice relating to the regulation of such research'. ${ }^{31}$ Standardisation is accomplished through various means, including the introduction and maintenance of:

- SOPs to ensure procedural consistency across RECs;

- template research application forms - including information sheets, consent forms and research protocols - for researchers to devise more thorough and ethically robust applications;

- template review forms for REC members to complete when reviewing applications; and

- systems of accreditation, qualification or certification of RECs to encourage mutual trust in each REC's processes of review.

It must be said, though, that while many commentators support standardisation as a way to drive consistency and fairness in ethics review, others blame standardisation for the growth of an undesirable 'tick-box' approach that many see as defining REC work today. This, however,

${ }^{24}$ Health Research Authority, 'Proportionate Review: Information and Guidance for Applicants', www.hra.nhs.uk/ documents/1022/proportionate-review-information-guidance-document.pdf.

25 See e.g. E. Dove et al., 'Ethics Review for International Data-Intensive Research', (2016) Science, 351(6280), 1399-1400.

${ }^{26}$ The Federal Policy for the Protection of Human Subjects ('Common Rule'), 45 C.F.R. \$ 46, Subpart A; The Federal Policy for the Protection of Human Subjections, 82 FR 7149, at 7265 (19 January 2017).

${ }^{27}$ Uganda National Council for Science and Technology, 'National Guidelines for Research involving Humans as Research Participants', (UNCST, 2014), s. 4.5.5, para. c

${ }_{28}$ Clinical Trials Ontario, www.ctontario.cal.

${ }_{29}$ Victoria State Government, 'National mutual acceptance', (health.vic, 2018) www2.health.vic.gov.au/about/clinicaltrials-and-research/clinical-trial-research/national-mutual-acceptance.

$3^{\circ}$ E. Dove, 'Requiring a Single IRB for Cooperative Research in the Revised Common Rule: What Lessons Can Be Learned from the UK and Elsewhere?', (2019) Journal of Law, Medicine 6 Ethics, 47(2), 264-282.

${ }^{31}$ Care Act 2014, s. 111(1). 
might be a product of the continued confusion about whether we see RECs as philosophically attuned ethics deliberation entities rather than as regulatory assessors situated within a wider health research ecosystem. I have argued above that the latter view is more accurate.

Third, the emerging concept of regulatory stewardship may have resonance in reforming the regulatory design of research ethics review to better account for the network of actors involved in bringing an application through the various regulatory thresholds in the research lifecycle. A key finding from recent empirical investigation ${ }^{32}$ is the ability of actors within the health research regulatory space to serve as 'regulatory stewards'. Research suggests that regulatory stewardship involves different actors - including RECs and others involved in the regulation of health research - helping researchers and sponsors navigate complex regulatory pathways and work through the thresholds of regulatory approvals. Collective responsibility, as a component of regulatory stewardship, requires relevant actors to work together to design and conduct research that is ethical and socially and scientifically valuable and that ultimately aims to improve human health. This can only be accomplished if a framework delineates how and when regulators and regulatees should communicate with one another and makes clear who has what responsibility and role to be played (if any) at each stage in the research lifecycle.

The regulatory environment for research ethics review could be designed to provide clearer channels for RECs - and members within them who may have closer contact with researchers and sponsors - and their own managing regulators (e.g. institutions, ministries, regulatory authorities) to engage with researchers and sponsors in improving the quality of research protocols and applications, and in working through law, regulation, and regulatory approvals. These communicative channels may include online toolkits and more personalised support via email, telephone, or digital meetings.

All of this would have the added advantage of engaging multiple actors in earlier stages of the research design process, including on the actual ethics issues (or not) that arise. Where these are considerable, the further downstream ethics review will still have a role to play; however, where these are minimal or negligible, they might be addressed sooner in the regulatory pathway, leaving the REC to undertake its regulatory role more efficiently and effectively.

\subsubsection{Future Directions for Researching Research Ethics Review}

Further empirical evidence is needed to investigate questions about extant research ethics review processes and to test new models that seek to improve REC efficiency and effectiveness. There have been few in-depth qualitative studies of RECs focusing on assessment of regulatory design. This undermines effective regulation, as policymakers and regulators - through state actors or otherwise - increasingly seek to develop regulation through intricately documented evidence of problems and the effects of regulation on society. There is a need for qualitative research that explores how and why RECs make the decisions they do, and how the nested dynamics of RECs and central 'managing' regulators play into decisions. ${ }^{33}$

$3^{2}$ Dove, 'Regulatory Stewardship'; see also G. Laurie et al., 'Charting Regulatory Stewardship in Health Research: Making the Invisible Visible’, (2018) Cambridge Quarterly of Healthcare Ethics, 27(2), 333-347.

33 S. Nicholls et al., 'A Scoping Review of Empirical Research Relating to Quality and Effectiveness of Research Ethics Review', (2015) PLOS ONE, 10(7), eo133639; see also, for a US example of research in this area, AEREO: The Consortium to Advance Effective Research Ethics Oversight, www.med.upenn.edu/aereo/. 
Documented problems of RECs have largely relied on evidence and anecdote proffered by researchers. While there is a welcome growing corpus of empirical literature on RECs, ${ }^{34}$ more evidence is needed from regulatory scholars who can go inside RECs to test new models via pilot studies or randomised controlled trials; or who can examine how RECs, both as individual members and as a body, see themselves and their committee in a changing regulatory environment, and can go inside regulatory bodies to gather the regulators' perspective on the roles of a REC within the health research regulatory space. Research ethics review thus remains an area ripe for investigation.

\subsection{CONCLUSION}

In this chapter, I have argued that RECs have become regulatory entities in their own right, governed by - depending on the jurisdiction - institutions, central regulatory agencies, administrative staff and offices, standardised forms and communications, and lengthy governance arrangements and SOPs. Just as some legal scholars speak of 'juridification', ${ }^{35}$ which is an encroachment of law into ever more aspects of our society, so too might we speak of ethics review increasingly 'colonising' the health research regulatory space, structured according to the logic of its codes and customs. When RECs were first coming into being in the 196os, Harvard Law Professor Louis Jaffe opined that " $[\mathrm{a}]$ general statutory requirement requiring institutional committees in any "experiment" would raise monstrous problems of interpretation, would unduly complicate medical practice, and would add unnecessary steps to experiments where the risks to the subject or patient are trivial. ${ }^{36}$

Yet this is where we stand today, with REC review required formally by law or informally by policy for an array of health research, from the trivial to the complex and risky, albeit with more proportionate review processes than occurred previously. Over time, like all of health research, the regulatory space in which RECs are situated has expanded, along with the paperwork and resources researchers must dedicate in order to pass over the 'ethics hurdle'.

At the same time, scholars remind us that: "The role of the Research Ethics Committee is to advise. It does not itself authorise research. This is the responsibility of [another] body under whose auspices the research will take place'. ${ }^{37}$ While technically accurate - at least in many jurisdictions - this fails to appreciate the power of a REC to control what knowledge can be produced and how that knowledge is shaped. RECs, as noted previously, are a form of social control of science. The 'advisory' role of a REC masks its profound ability to impact health research, which is precisely why RECs have faced such criticism and undergone reform. They are not minor actors in the health research regulatory space; on the contrary, they may be

34 For empirical studies of IRBs in the USA, see e.g. Stark, Behind Closed Doors; Babb, Regulating Human Research; Klitzman, The Ethics Police; J. F. Jaeger, 'An Ethnographic Analysis of Institutional Review Board Decision-Making' ( $\mathrm{PhD}$ thesis, University of Pennsylvania 2006). For empirical studies of RECs in the UK, see e.g. A. Hedgecoe et al., 'Research Ethics Committees in Europe: Implementing the Directive, Respecting Diversity', (2006) Journal of Medical Ethics, 32(8), 483-486; J. Neuberger, Ethics and Health Care: The Role of Research Ethics Committees in the United Kingdom (King's Fund Institute, 1992).

35 G. Teubner, 'Juridification: Concepts, Aspects, Limits, Solutions' in G. Teubner (ed.), Juridification of Social Spheres (Berlin: Walter de Gruyter \& Co, 1987).

${ }^{36}$ L. Jaffe, 'Law as a System of Control', (1969) Daedalus, 98(2), 406-426, 412.

37 I. Kennedy and P. Bates, 'Research Ethics Committees and the Law' in S. Eckstein (ed.), Manual for Research Ethics Committees, 6th Edition (Cambridge University Press, 2003), pp. 15-17, p. 16. 
among the most important. And, as I have stressed, the obligations imposed on RECs have only increased over time as myriad regulation is brought to bear on them. Ethics and regulation must go hand-in-hand - indeed, one might say that the process of research ethics review must be co-produced with regulation, and regulation and ethical judgement are codependent. It is crucial that we appreciate the respective roles of each when it comes to entities such as the REC. This chapter has sought to reveal how we can better understand and deliver these dual roles. 